\title{
Editorial \\ Anti-tumour necrosis factor therapy and B cells in rheumatoid arthritis
}

\author{
Maria J Leandro
}

Centre for Rheumatology, University College London, Windeyer Building, Room 318, 46 Cleveland Street, London W1T 4JF, UK

Corresponding author: Maria J Leandro, maria.leandro@ucl.ac.uk

Published: 6 October 2009

Arthritis Research \& Therapy 2009, 11:128 (doi:10.1186/ar2809)

This article is online at http://arthritis-research.com/content/11/5/128

(c) 2009 BioMed Central Ltd

See related research by Souto-Carneiro et al., http://arthritis-research.com/content/11/3/R84

\begin{abstract}
The efficacy of B-cell depletion therapy in rheumatoid arthritis (RA) has led to a renewed interest in B cells and their products and the role they play in the pathogenesis of the disease. Agents blocking tumour necrosis factor (TNF) are also very effective in the treatment of RA. It has long been known that the use of anti-TNF therapy can be associated with development of anti-nuclear and anti-double-stranded DNA antibodies and, more rarely, a lupus-like syndrome. Recently, studies have been published investigating further possible effects of anti-TNF agents on B cells and whether these could contribute to their effectiveness in RA.
\end{abstract}

Both blocking tumour necrosis factor (TNF) and depleting B cells are effective therapeutic strategies in rheumatoid arthritis (RA). Recently, some articles have focused on possible effects of anti-TNF agents on B cells, exploring whether this could contribute to the efficacy of these agents in the treatment of RA. In a study published in a recent issue of Arthritis Research \& Therapy, Souto-Carneiro and colleagues [1] described a decrease in circulating pre-switch $\lg { }^{+} \mathrm{CD} 27^{+}$memory $B$ cells in patients with RA when compared with normal controls. Patients with longer disease duration had increased frequency of post-switch lgD-CD27+ memory $\mathrm{B}$ cells when compared with patients with shorter disease duration or normal controls. Treatment with infliximab was associated with an increase in the frequency of total and pre-switch memory $B$ cells whereas no significant changes were seen in patients treated with only methotrexate.

All B cells express CD19. Naive B cells exit the bone marrow at a transitional stage, already expressing both $\lg M$ and $\lg D$ but expressing higher levels of CD38 and CD24 than naive mature B cells and still expressing low levels of CD10 [2]. CD27 is a marker of somatic mutation and therefore of memory B cells [3]. Memory B cells are frequently subdivided into pre-switch memory $B$ cells, expressing $\lg \mathrm{D}$ and $\lg \mathrm{M}$, and post-switch memory $B$ cells, no longer expressing $\lg D$ and expressing $\lg G$ or $\lg A$.

A few other studies have looked at circulating B-cell subsets in RA [2-4]. The results described are not consistent. This may be due to variability within the different RA cohorts (age, disease duration, disease activity and treatment with anti-TNF or other disease-modifying anti-rheumatic drugs) and differences between control groups. It may also be due to absence of a true pattern of changes in circulating B-cell subpopulations in patients with RA. Study of possible effects of anti-TNF therapy on circulating B-cell subsets has also shown variable results $[1,4-6]$. A cross-sectional study found a decreased frequency of circulating total CD27+ memory $B$ cells in patients with RA treated with etanercept when compared with patients treated with methotrexate or when compared with healthy controls [6]. Both pre- and postswitch memory B-cell subset proportions were decreased [6]. Although the results are not comparable, the differences associated with anti-TNF therapy in this study are in contrast with the changes described by Souto-Carneiro and colleagues [1]. Other cross-sectional studies did not find differences between patients on anti-TNF therapy and patients on other treatments when the frequency of the same B-cell subsets or expression on $B$ cells of different chemokine receptors was compared $[4,5]$.

Anti-TNF agents are thought to act mainly by blocking TNF at the local site of production - the synovium - with the consequent blocking of TNF effects on cytokine regulation (in particular, reducing levels of interleukin-6 [IL-6] and IL-1), cell recruitment (reduced expression of adhesion molecules and chemokines, resulting in decreased migration of circulating 
leucocytes into inflamed joints), angiogenesis and tissue destruction [7]. However, TNF and a related cytokine, lymphotoxin alfa $(L T \alpha)$, also play an important role in the development and homeostasis of secondary lymphoid organs [8]. Studies in mice suggest that TNF plays a major role in the formation of Peyer's patches and the organisation of the spleen, particularly the compartmentalisation of $B$ and $T$ cells and the establishment of the marginal zone [8]. In general, TNF and soluble LT $\alpha$ are thought to have overlapping roles in this setting, although LT $\alpha$ may play a predominant role in promoting the formation of tertiary lymphoid tissue at sites of chronic inflammation $[8,9]$. Whether differences between the two main groups of anti-TNF agents, the receptor fusion protein (etanercept) and the monoclonal anti-TNF antibodies (infliximab and adalimumab), could have any consequence on the effect of these agents on B-cell homeostasis or function is not known. The main clinical differences between these agents are usually attributed to the fact that the monoclonal antibodies may be able to lyse cells that express TNF on their surface. Etanercept, the receptor fusion protein, can bind not only TNF but also LT $\alpha$. Nevertheless, both treatment with infliximab and adalimumab and treatment with etanercept have been associated with decreased lymphoid follicle structures in the inflamed synovia [10].

Souto-Carneiro and colleagues [1] suggest that the decrease in circulating pre-switch memory B cells in RA patients is due to the accumulation of these cells in the inflamed synovia and that blocking the effects of TNF decreases trafficking into and retention of $B$ cells in the synovia, thereby increasing their proportion in the peripheral blood. However, both pre- and post-switch memory $B$ cells can be found in the synovia and no changes were seen in the post-switch subset following treatment with infliximab. In mice, the absence of TNF affects the organisation of the spleen marginal zone [9]. In humans, at least a subset of the circulating pre-switch memory $B$ cells is thought to be related to the marginal zone in the spleen $[11,12]$. An alternative explanation for the changes observed when patients were treated with infliximab could be an increased formation or circulation of pre-switch memory $B$ cells by interfering with follicular dendritic cell function and germinal centre formation in secondary lymphoid tissues, including the spleen [12]. Recently, a decrease in follicular cell networks and germinal centre structures was described in tonsils of RA patients treated with etanercept [6].

It is still unclear what effects anti-TNF treatment can have on $B$ cells in RA and whether any effects influence the efficacy of these agents. In patients with RA, anti-TNF agents sometimes can induce a sustained response that persists after the drug is stopped. It will be interesting to investigate whether any effects that anti-TNF agents can have on B-cell function and homeostasis could contribute to this sustained response.

\section{Competing interests}

The author declares that they have no competing interests.

\section{References}

1. Souto-Carneiro MM, Mahadevan V, Takada K, Fritsch-Stork R, Nanki T, Brown M, Fleisher TA, Wilson M, Goldbach-Mansky R, Lipsky PE: Alterations in peripheral blood memory B cells in patients with active rheumatoid arthritis are dependent on the action of tumour necrosis factor. Arthritis Res Ther 2009, 11: R84.

2. Sims GP, Ettinger R, Shirota $Y$, Yarboro $\mathrm{CH}$, Illei GG, Lipsky PE: Identification and characterization of circulating human transitional B cells. Blood 2005, 105:4390-4398.

3. Klein U, Rajewsky K, Kuppers R: Human Immunoglobulin (lg) $\mathrm{M}^{+}$IgD+ peripheral blood B cells expressing the CD27 cell surface antigen carry somatically mutated variable region genes: CD27 as a general marker for somatically mutated (memory) B cells. J Exp Med 1998, 188:1679-1689.

4. Henneken M, Dörner T, Burmester GR, Berek C: Differential expression of chemokine receptors on peripheral blood $B$ cells from patients with rheumatoid arthritis and systemic lupus erythematosus. Arthritis Res Ther 2005, 7:R1001-1013.

5. Fekete A, Soos L, Szekanecz Z, Szabo Z, Szodoray P, Barath S, Lakos G: Disturbances in B- and T-cell homeostasis in rheumatoid arthritis: suggested relationships with antigendriven immune responses. J Autoimmun 2007, 29:154-163.

6. Anolik JH, Ravikumar R, Barnard J, Owen T, Almudevar A, Milner EC, Miller $\mathrm{CH}$, Dutcher PO, Hadley JA, Sanz I: Cutting edge: anti-tumor necrosis factor therapy in rheumatoid arthritis inhibits memory B lymphocytes via effects on lymphoid germinal centres and follicular dendritic cell networks. J Immunol 2008, 180:688-692.

7. Maini RN, Feldman M: How does infliximab work in rheumatoid arthritis? Artrhitis Res 2002, 4(suppl 2):S22-S28.

8. Ware CF: Network communications: lymphotoxins, LIGHT, and TNF. Annu Rev Immunol 2005, 23:787-819.

9. Drayton DL, Ying X, Lee J, Lesslauer W, Ruddle NH: Ectopic LTalfabeta directs Iymphoid organ neogenesis with concomitant expression of peripheral node addressin and a HEVrestricted sulfotransferase. J Exp Med 2003, 197:1153-1163.

10. Cañete JD, Celis R, Moll C, Izquierdo E, Marsal S, Sanmartí R, Palacín A, Lora D, de la Cruz J, Pablos JL: Clinical significance of synovial lymphoid neogenesis and its reversal after antitumour necrosis factor $\alpha$ therapy in rheumatoid arthritis. Ann Rheum Dis 2009, 68:751-756.

11. Weller S, Braun MC, Tan BK, Rosenwald A, Cordier C, Conley ME, Plebani A, Kumararatne DS, Bonnet D, Tournilhac O, Tchernia G, Steiniger B, Staudt LM, Casanova JL, Reynaud CA, Weill JC: Human blood IgM "memory" B cells are circulating splenic marginal zone B cells harboring a prediversified immunoglobulin repertoire. Blood 2004, 104:3647-3654.

12. Tangye SG, Good KL: Human IgM+CD27+ B cells: memory B cells or "memory" B cells? J Immunol 2007, 179:13-19. 